apuntesuniversitarios.upeu.edu.pe

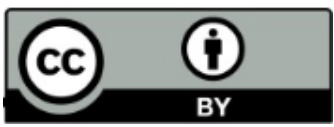

Apuntes Universitarios, 2020: 10(4), octubre-diciembre

ISSN: 2304-0335 DOI:https://doi.org/10.17162/au.v10i4.513

\title{
Martín Vizcarra Cornejo en el poder: los presuntos actos de corrupción en su contra y su lucha contra la corrupción
}

\section{Martín Vizcarra Cornejo in power: the alleged acts of corruption against him and his fight against corruption}

\author{
Marco Antonio Lovón Cueva ${ }^{1 \mathrm{a}}$, Hendrik Anderson Camarena Champi ${ }^{2}$ y \\ María Mercedes Palomino Gonzales ${ }^{3}$
}

\begin{abstract}
Universidad Peruana de Ciencias Aplicadas, Lima, Perú ${ }^{1}$
Universidad Nacional Mayor de San Marcos, Lima, Perú ${ }^{2}$

Universidad Nacional Mayor de San Marcos, Lima, Perú ${ }^{3}$

iD Orcid ID: https://orcid.org/0000-0002-9182-6072 1

Orcid ID: https://orcid.org/0000-0002-4467-2605²

Orcid ID: https://orcid.org/0000-0002-4876-2755
\end{abstract}

Recibido: 15 de marzo de 2020

Aceptado: 03 de agosto 2020

\begin{abstract}
Resumen
El presente trabajo de investigación presenta un análisis acerca de Martín Vizcarra como actor político en el marco de las consecuencias políticas y judiciales en relación con el tema de corrupción que se le acusa, primero, como gobernador regional de Moquegua (2011-2014), luego, como Ministro de Transportes y Comunicaciones del Perú (2016-2017), y, posteriormente, como máxima autoridad del país (2018-2021). Metodológicamente, se emplea la información obtenida de la documentación periodística y la estadística. En el trabajo se señala que Vizcarra construye estratégicamente una identidad política con la que se opone a la corrupción y con la que contrarresta las acusaciones o denuncias de delitos durante sus distintas gestiones contra la administración pública peruana para favorecer su imagen como político.
\end{abstract}

Palabras clave: Martín Vizcarra, corrupción, reformas políticas, gobierno, Moquegua

\footnotetext{
Abstract

This research presents an analysis of Martín Vizcarra as a political actor in the framework of the political and judicial consequences related to the corruption issue he is accused of, first, as regional governor of Moquegua (2011-2014), then as Minister of Transport and Communications of Peru

${ }^{a}$ Correspondencia al autor

E-mail: marcolovon@ hotmail.com
} 
(2016-2017), and, later, as the highest authority of the country (2018-2021). Methodologically, the information obtained from journalistic documentation and statistics is used. The work points out that Vizcarra strategically builds a political identity with which he opposes corruption and with which he counteracts accusations or denunciations of crimes during his different actions against the Peruvian public administration in order to favor his image as a politician.

Keywords: Martín Vizcarra, corruption, political reforms, government, Moquegua.

\section{Introducción}

Martín Vizcarra, ingeniero de profesión, asumió la presidencia de la República el 23 de marzo de 2018, como consecuencia de la renuncia del hasta entonces mandatario Pedro Pablo Kuczynski (PPK), presionado tras las denuncias por sus vínculos con la constructora brasileña Odebrecht vinculada a un caso de lavado de activos (El Comercio, 2018). Se trataba del mayor escándalo de corrupción de Latinoamérica, en que una empresa pagó sobornos en al menos una docena de países según la investigación realizada del departamento de Justicia de Estados Unidos (DW, 2017). Así, Vizcarra heredó la banda presidencial en un contexto de una profunda crisis política. Sobre la renuncia de Kuczynski, Ponce de León, \& García Ayala (2019, p. 342) señalan que "En Perú, como en pocos países de la región, el destape de la mega corrupción de Odebrecht y de otras constructoras tuvo un efecto demoledor sobre las principales figuras políticas del país (...) [que] se encuentran investigadas por la Fiscalía”.

Dicha crisis estuvo marcada por el enfrentamiento del Ejecutivo con el Poder Legislativo, dominada por una mayoría fujimorista, opositora al Gobierno. En el mandato de Kuczynski, la relación Ejecutivo-Legislativo se caracterizó por una asidua confrontación, procedente sobre todo desde el partido Fuerza Popular, que ostentaba una amplia mayoría de escaños (Arce, \& Incio, 2018), y cuya lideresa iba siendo investigada por temas de corrupción desde el Estado. Esa confrontación generó un profundo deterioro entre ambos poderes (Ackerman, 2007, Alcántara, \& Sánchez López, 2001, Campos, 2014), lo que evidenció un clivaje político (Soto, 2018), y una afectación específica al sistema de representación y a la institucionalidad.

Martín Vizcarra asumió el poder en un contexto en el que se le acusaba del registro de 34 investigaciones preliminares en su contra (Gestión, 2016a); parte de ellas, por la gestión como gobernador regional en Moquegua y otra cuando era titular de la cartera del Ministerio de Transportes y Comunicaciones (MTC) del Perú por aparentes irregularidades en contratos que 
involucraban grandes proyectos públicos. A Vizcarra se le han imputado presuntos actos irregulares en sus funciones públicas, aunque él las ha subestimado señalando que el fondo de esas acusaciones solo buscan "desestabilizar al Gobierno" frente a su lucha contra la corrupción (Lamula.pe, 2019). Y a pesar de las denuncias, Vizcarra ha organizado un discurso de lucha anticorrupción como una estrategia que favorece su imagen. Este discurso le sirve para mostrar un gobierno que contiene el enrevesado escenario político del país y que le permite construir, como sostiene, un Perú con democracia fortalecida. Y aunque su mandato aún no termina, en esta investigación, se pretende ofrecer una descripción general de él como actor político (García, 2007) en los diversos escenarios: regional y nacional. Se intenta realizar un análisis político de sus gestiones desde la Ciencia Política (Tanaka, 2019).

En el trabajo, buscamos responder la siguiente pregunta: ¿Cómo ha actuado Martín Vizcarra Cornejo en los distintos escenarios políticos en medio de denuncias en su contra que lo inculpan por presunta corrupción y cómo actúa en relación con ellas hoy? El objetivo principal de este trabajo de investigación radica en presentar un análisis de Martín Vizcarra Cornejo como actor político en relación con el tema de la corrupción en sus facetas de gobernador regional de Moquegua, ministro de Transportes y Comunicaciones y presidente de la República.

Este artículo de investigación utiliza como metodología el análisis descriptivo. Hasta el momento no hay estudios académicos específicos sobre Martín Vizcarra. Por ello, emplearemos la documentación periodística como fuente principal para recoger la información necesaria sobre su posición formal, los comportamientos, los intereses, la toma de decisiones, las actitudes y el entorno de oportunidad de Vizcarra, así como la información estadística de datos obtenidos de encuestas, como una forma de revelar las percepciones porcentuales que refleja.

El artículo se ordena de la siguiente manera: se presenta un contexto interno y externo general sobre el gobierno de Vizcarra; luego, se estudia su papel como actor político; seguidamente, se realiza una evaluación de su gestión; finalmente, se proponen las conclusiones. 


\section{Contexto interno y externo}

\section{Contexto político peruano}

Durante el 2018, el Perú presenció una de las crisis políticas más mediáticas y controversiales de los últimos años (Arce, \& Incio, 2018), que dio paso a una inestabilidad política (Coelho, 2012).

Pedro Pablo Kuczynski, quien construyó una buena imagen como candidato presidencial (Mäckelmann, 2017), y a pesar de que logró ocupar el sillón presidencial, enfrentó un largo malestar, asociado con el caso Lava Jato. El 9 de febrero de 2017 la Justicia peruana dictó una orden de encarcelamiento contra el exmandatario Alejandro Toledo (2001-2006), del que Kuczynski fue primer ministro y ministro de Economía, por actos de corrupción vinculados a Odebrecht. Un par de semanas después, el expresidente Ollanta Humala (2006-2011) aparecía también como presunto receptor de dinero ilegal. El caso Odebrecht alcanzó a Kuczynski el 6 de marzo de 2017, cuando la Procuraduría Anticorrupción solicitó investigarlo.

Kuczynski cumple su primer año con una muy baja popularidad y el Congreso no otorga la confianza a su gabinete, lo que refuerza el quiebre de sus relaciones. En noviembre de 2017 salen a la luz investigaciones periodísticas sobre una asesoría realizada por Kuczynski a Odebrecht y algunos indicios de que la empresa brasileña habría contribuido a su campaña presidencial. El 15 de diciembre del 2017, Kuczynki logra sortear el primer pedido de vacancia al que se le procesaba por presunta incapacidad moral; esto gracias a la abstención de 10 congresistas de la bancada fujimorista. No obstante, su popularidad siguió en descenso y la población mostró su malestar hacia su gestión, y la empezaba a desaprobar (Acevedo, 2017). Días después, Kuczynski concede el indulto para el exmandatario Alberto Fujimori, quien cumplía entonces 10 años de prisión por delitos de lesa humanidad. Frente a ello, distintas asociaciones, grupos sociales y civiles, manifestaron su descontento calificando este hecho como una aparente negociación:

Kuczynski se vio cercado por la movilización de un sector de la población, las sesiones de la Corte Interamericana de Derechos Humanos (Corte IDH) y, finalmente, el inicio de un segundo proceso de vacancia en su contra. Durante los últimos días del 2017 y los primeros del siguiente, se realizaron múltiples marchas en Lima y en distintas partes del país en contra del indulto a Fujimori, lideradas por organizaciones de estudiantes y colectivos sociales en defensa de los derechos humanos. Además de que la mayoría en la población consideraba el indulto como el producto de una negociación entre el presidente y la minoría fujimorista rebelde. (Ponce de León \& García Ayala, 2019, p. 348) 
Tanto el descontento de la población como una fuerza mayoritaria en el Congreso fueron arremetiendo en contra del expresidente. En marzo del 2018, el parlamento aprobó un nuevo pedido de vacancia que nunca llegó a concretarse debido a la ausencia del proceso de votos; sin embargo, e inevitablemente, este escenario no resultaría en una victoria para Kuczynski, ya que paralelamente a dicho proceso de vacancia se le acusaba de supuestas colaboraciones $\mathrm{y}$ transferencias emitidas con la constructora Odebrecht. Kuczynski, en medio de estas declaraciones, tuvo que negar frente a la opinión pública que tal hecho haya ocurrido. No obstante, el 21 de marzo de 2018 oficializó su renuncia.

En ese clima político, Martín Vizcarra Cornejo, quien ocupaba el cargo de primer vicepresidente, asumió la presidencia (Cuba, 2018). Este último había incluido a Vizcarra en su partido político "Peruanos por el Cambio" en la campaña presidencial 2015 y 2016. Según Carlos Bruce integrante del partido, necesitaban a un "provinciano" para ganar votos porque en el partido casi todos eran blancos (RPPNoticias, 2019). Dentro del partido, cumplió el papel de operador y amplió los intereses partidarios. Vizcarra fue elegido por Kuczynski para ejercer el cargo en la cartera del Ministro de Transportes y Comunicaciones, el mismo día que PPK asumió la Presidencia el 28 de julio de 2016. En el poder, el ingeniero y entonces ya electo presidente de la República, era percibido de forma positiva incluso por las bancadas opositoras a PPK. Se vio favorecido a inicios de su gobierno por haber contado con la experiencia en el Gobierno Regional de Moquegua (GRM) años atrás.

El nuevo presidente, en un mensaje a la nación, anunció como prioridades de su gestión la lucha contra la corrupción, la educación, la estabilidad institucional y la recuperación de la gobernabilidad. Luego de la imposición de la banda, Vizcarra - a diferencia de lo ocurrido con Kuczynski en julio de 2016 - fue aplaudido por los congresistas de todos grupos políticos, incluidos Fuerza Popular, de Keiko Fujimori. "Llegó el momento de decir basta" a este período de "zozobra institucional. Lo que ha sucedido debe marcar el punto final de una política de odio y confrontación, y debemos señalar objetivos claros para el Perú", exigió al Parlamento (Fowks, 2018, párr. 2).

El país se encontraba en una incertidumbre profunda, a partir de la cual el gobierno de Vizcarra se hace cargo, e incorpora nuevos elementos que guíen la administración pública. El nuevo presidente reconoció, en primer lugar, la existencia de una inestabilidad e ineficiencia política y, para solucionar ello, propuso a los congresistas una convivencia con el objetivo de paliar la corrupción. Después, Vizcarra se enfrentaría al destape de los audios de la vergüenza, que 
presuntamente vinculaban a funcionarios del Poder Judicial y el Consejo Nacional de la Magistratura con tráfico de influencias y actos de corrupción (BBC, 2018).

Frente a este caso, Vizcarra como jefe de Estado propuso una reforma política (Carbonell, 2006) y judicial para recuperar la credibilidad y la confianza ciudadana en el sistema judicial peruano. Empero, la obstrucción y confrontación constante con la fuerza mayoritaria opositora del Congreso, entorpecieron los procedimientos. La decisión tomada por el presidente fue inmediata. Su presidente del Consejo de Ministros planteó la cuestión de confianza al parlamento para poder aprobar las cuatro reformas que se le planteó al Legislativo. Bajo esta medida tomada por el Ejecutivo, el Congreso se vio en la facultad de aprobar las reformas políticas.

El presidente Vizcarra pidió a los electores votar en contra de la bicameralidad, aduciendo que el Congreso había desnaturalizado su propuesta original. Las propuestas, con excepción de la bicameralidad, fueron aprobadas por la mayoría de los peruanos. El Ejecutivo salió airoso de esta batalla en contra de la corrupción, como lo enmarcó el gobierno en busca de ganar el apoyo de la población. Así, más del 85\% de los votantes respaldaron las tres primeras propuestas que favorecían a la transparencia del financiamiento de los partidos políticos, la no reelección de congresistas y la reforma del CNM; mientras que un $90 \%$ rechazó la última reforma que concernía a la existencia de dos cámaras en el Congreso de la República. (León, 2019, p. 351)

Todo lo acontecido se iba desarrollando en un contexto, en cierta medida, favorable para Martín Vizcarra (CPI, 2018). Pero a medida que confrontaba al parlamento con medidas populistas, en paralelo se generaron reacciones en la oposición que, en detrimento del presidente, le producían consecuencias que mermaron su aprobación. Los congresistas criticaron a Vizcarra: “Carlos Tubino aseveró [...] que con la denuncia que indica que una empresa de propiedad del presidente Vizcarra fue proveedora del consorcio CONIRSA en la carretera interoceánica se denota que el jefe del Estado no ha sido transparente" (Perú21, 2019a, párr. 1). Por otro lado, Pedro Chávarry, entonces Fiscal de la Nación, y antes de ser incluido en un caso de crimen organizado en el periodo de Vizcarra, sostendría que el caso de la construcción del aeropuerto de Chincheros sería acreditado e investigado para denunciar a los funcionarios que fueron partícipes de posibles actos de corrupción, en referencia al presidente Vizcarra (LaMula.pe, 2018).

El procurador anticorrupción Amado Enco calificó de "sumamente grave" el reciente informe de la Contraloría General de la República que advierte una responsabilidad administrativa, penal y civil en 14 funcionarios del Gobierno Regional de Moquegua por la construcción del hospital regional durante la gestión de Martín Vizcarra en el período 2011-2014. (RPPNoticias, 2019) 
Martín Vizcarra una vez que asumió la presidencia y al oponerse a las fuerzas políticas tradicionales entró en una lucha de acusaciones.

\section{Contexto internacional}

En el plano regional e internacional, Vizcarra ha cumplido un rol de continuador de propuestas.

En el plano económico, el mundo se encuentra en plena desaceleración económica mundial, que afectan al gobierno de Vizcarra (RTV, 2019). China y EE. UU. no solo no movilizan el mercado mundial, sino que han entrado en condicionamientos hacia ciertos países (Urdinez, 2017) y enfrentamientos comerciales entre ellos (Laufer, 2019). Y Vizcarra al igual que los anteriores presidentes decidió mantener las mismas políticas macroeconómicas y alianzas regionales e internacionales que sostienen el sistema mundial.

En el año 2017, en la capital de Perú se llevó a cabo, tras la Declaración de Lima, el establecimiento del organismo internacional Grupo de Lima, cuyos integrantes de los gobiernos de Chile, Perú, Argentina, Brasil, Canadá, Colombia, Costa Rica, Honduras, Paraguay, Panamá, Guatemala y el gobierno interino de Juan Guaidó buscaban resolver pacífica y democráticamente la crisis interna que aqueja a la nación venezolana desde que el presidente Nicolás Maduro asumió el poder (Lovón, \& Pita, 2016). Al respecto, Vizcarra continuó con el rol que Kuczsynki tuvo en el Grupo de Lima. Dentro de este periodo, Vizcarra y Maduro mantuvieron posiciones e interpretaciones distintas sobre qué significa gobernar un país desde la democracia (La Tercera, 2019). Maduro criticó la manera que Vizcarra conducía el Grupo de Lima y el país. Y Vizcarra no lo reconocía como presidente (Andina, 2019). Al igual que PPK lo percibía como antidemocrático.

Para el año 2019, múltiples incendios acaecidos en la Amazonía devoraron gran parte del ecosistema forestal. Este hecho, por una parte, despertó una desmedida y alarmante preocupación en todo el mundo, sobre todo en países latinoamericanos, debido a la impactante afectación que le iba ocasionando a la fauna y flora amazónica. El gobierno brasileño de Jair Bolsonaro fue criticado por la morosa respuesta que emprendía para mitigar los incendios tropicales que más pérdidas provocaban en su región, más que en Perú (Wayka, 2019). Frente a ello, Vizcarra junto con otros presidentes de Colombia, Brasil, Ecuador, Bolivia, Guyana y Surinam suscribieron el Pacto Amazónico de Leticia, un instrumento que sirve para la protección, la conservación y el desarrollo 
sostenible de la Amazonía (Rocha, 2019). Vizcarra no solo planteó proteger los ecosistemas, sino también sostuvo la lógica del desarrollo sostenible que presidentes anteriores ya han formulado para el Perú.

\section{Vizcarra como actor político}

\section{Vizcarra como gobernador regional: Casos archivados}

En las elecciones regionales de 2010, Martín Vizcarra, miembro vigente por “Integración Regional Por Ti”, logró alcanzar la cantidad de 38.549 \% de los votos emitidos en la región de Moquegua, superando los números de porcentaje del candidato Zenón Cuevas, quien postulaba con el partido "Frente de Integración Regional Moquegua Emprendedora Firme", pues solo alcanzó el 28.016 \%. De esta manera, Martín Vizcarra Cornejo consiguió la Presidencia del Gobierno Regional de Moquegua (GRM) (RPPNoticias, 2010).

Como presidente regional, Vizcarra priorizó el área educativa por encima de otras problemáticas sociales que aquejaban a la región de Moquegua. Con más de 190,000 habitantes y un territorio que alcanza los 15,734 kilómetros cuadrados, Moquegua, durante la gestión del actual presidente de la República, sacó adelante diferentes proyectos para la construcción de colegios, centros de salud, espacios de conectividad, entre otros. Moquegua destacó por ser una de las regiones más competitivas y ser a nivel nacional una de las economías de menos riesgo.

Al culminar el mandato de Vizcarra en el 2014, la incidencia de la pobreza en Moquegua se ubicaba entre $10.8 \%$ y $13.4 \%$, reduciéndose sustantivamente. En el último informe de la pobreza del INEI, del 2016, Moquegua continuaba en el quinto grupo con incidencia de pobreza (entre $9.6 \%$ y 12\%), junto con Arequipa, Madre de Dios, Callao, Lima, Tumbes y Ucayali. En el 2012, Moquegua comenzó a liderar el ranking de evaluación censal que mide la comprensión lectora y de matemáticas en escolares de primaria. Luego, en la última evaluación del 2016, Moquegua se ubicó en segundo lugar, solo superado por Tacna. Importa precisar que, a la fecha, la actividad productiva en la región de Moquegua se centra principalmente en los sectores minería, manufactura, construcción y servicios. (Lezama, 2018, p. 5)

A nivel regional, Martín Vizcarra obtuvo diversos cambios sustantivos que le permitieron a Moquegua cerrar brechas sociales y económicas. Él logró transformar y ubicar a esta región dentro de una de las más importantes durante los años 2011-2014, y mantiene hasta la actualidad compensables resultados estadísticos a nivel nacional (León, 2019). En su administración, los 
colegios de Moquegua se ubicaron en el primer lugar al participar de la evaluación censal de estudiantes realizada por el Ministerio de Educación (Minedu). Durante sus últimos años de gestión, logró el crecimiento del producto bruto interno (PBI) y la disminución en los niveles de pobreza a nivel regional. Vizcarra buscó hacer ver que Moquegua es el departamento que mayor desarrollo alcanzó en el último lustro.

La región Moquegua trepó del quinto puesto en el 2014 al tercer lugar en el 2015. Moquegua se ubicó con 44,37 puntos después de Lima y Callao, superando a Tacna y Arequipa. En economía ocupó el puesto 8, con 28,64 puntos, y a nivel de gobierno el puesto 2, con 51,52 puntos. "Moquegua se encuentra en el primer lugar en el índice del progreso social regional por dos razones fundamentales: Lo primero, ha podido gastar más del $85 \%$ de su presupuesto del gobierno regional a favor de la comunidad. Lo segundo, ha sabido llegar a procesos de concertación con el sector privado, sobre todo con las mineras y con el gobierno nacional para trabajar objetivos comunes a favor de la gente. Pero destaca muchísimo la gestión que hizo Vizcarra en su momento, por ello se termina ubicando en el primer lugar", explica Alexandra Ames, ex integrante de Centrum y autora del estudio sobre índice de progreso social (RPPNoticias, 2018, párr. 5).

Sin embargo, su mandato fue observado cuando formó parte del equipo de Kuczynski que buscaba llegar al gobierno central. En relación con su cargo como gobernador regional, la Procuraduría de Moquegua confirmó que Vizcarra como candidato a la primera vicepresidencia por el partido Peruanos Por el Kambio (PPK) poseía más de 30 denuncias, pero solo una se encontraba en instancia judicial. El representante de la Procuraduría de Moquegua, que se presentó como delegado de asuntos penales, Josep Valer, fue quien confirmó las denuncias en su contra por altos delitos de corrupción de funcionarios. De esto, la noticia central que más llamó la atención de la población fue el presunto pago irregular que se realizó exactamente el último día de gobierno entre funcionarios del gobierno regional de Moquegua, dirigido por Vizcarra, y el consorcio Ingenieros Civiles y Contratistas Generales S.A. (ICCGSA).

El 30 de diciembre del 2014, un día antes de que el ahora presidente Martín Vizcarra culminara su período como gobernador regional de Moquegua, se realizaron una serie de trámites en su gestión que, en menos de 24 horas, terminaron con la aprobación de un desembolso de S/41'869.086 a un consorcio integrado por ICCGSA por la construcción del hospital de la región. Para la contraloría, esta entrega de dinero fue irregular. Este Diario viajó a Moquegua para corroborar la información, entrevistarse con quienes intervinieron en el caso y ver cómo se encontraba el hospital. Según los documentos, las entregas de dinero fueron solicitadas y aprobadas por funcionarios de la gestión de Vizcarra, entre ellos el actual ministro de Transportes y Comunicaciones, Edmer Trujillo, quien en ese entonces era el gerente general del gobierno regional (Rojas, 2019, 1). 
En el 2019, la contraloría, a pesar de haber sido archivado el caso que involucraba al actual presidente, volvió a reabrirlo. Esta vez con evidencias que sustentaban la existencia de hechos mediante los cuales funcionarios del gobierno regional de Moquegua habrían beneficiado irregularmente a las empresas implicadas en el contrato. Aun así, con esta denuncia en contra, como presidente de la República, respondió a los diferentes medios de comunicación locales afirmando que las imputaciones en su contra no tendrían validez, ya que no han sido encontradas pruebas que las sustenten. Las denuncias fueron archivadas nuevamente hasta en dos oportunidades, hasta que una última apertura se dio a conocer en un contexto donde el presidente gozaba con una considerable aprobación por parte de la población, además del apoyo que recibió por haber disuelto el Congreso, de modo tal que no afectó popularmente la imagen política de Vizcarra.

Asimismo, Edmer Trujillo, quien había sido gerente general del Gobierno Regional de Moquegua en los años 2012-2014, salió a confrontar las afirmaciones realizadas ante la Contraloría en su nuevo informe sobre el pago irregular. Él consideraba que la gestión conducida por él y Vizcarra fue transparente, sobre todo en la ejecución de la obra. Al mismo tiempo, se mostró a disposición de colaborar con las investigaciones correspondientes, apoyándose en el hecho de que el informe no lo responsabilizaba:

No voy a especular. Estos hechos ya fueron investigados por la Fiscalía, se archivaron dos veces, pero estamos abiertos. Soy el principal interesado. Si ellos consideran que hay elementos para investigar nuevamente, allí estaremos. Asistiremos, como lo hemos hecho, a todas las citaciones que se puedan formular. Estamos convencidos de nuestro trabajo honesto y transparente. Por eso acompañamos ahora al presidente Vizcarra. Coincidimos con él plenamente en la necesidad de enfrentar la corrupción (Pereda, 2019, 13).

Vizcarra construyó una imagen de colaboración con las investigaciones que lo situaban en temas de corrupción.

\section{Vizcarra como ministro de Transportes y Comunicaciones: el caso chinchero}

En el año 2016, el presidente Pedro Pablo Kuczynski confirmó que el Ministerio de Transportes y Comunicaciones estaría a cargo de Martín Vizcarra Cornejo. En ese sentido, durante el año 2016 y parte del 2017, Vizcarra tuvo que lidiar con un problema que afectó gravemente al norte del país: el Fenómeno El Niño Costero, que dejó más de 100 fallecidos, alrededor de 364 heridos, más de 160,000 damnificados y más de 215,000 casas dañadas. Ante el desastre, diversas 
autoridades regionales y nacionales se unieron para evaluar, crear y ejecutar planes y medidas que ayuden a paliar las consecuencias.

Colegios clausurados, hospitales al borde del colapso, carreteras inundadas. Lluvias, desbordes y huaicos. El Fenómeno El Niño golpea al Perú desde Tumbes hasta Arequipa. Este es un mapa de los principales problemas que viven las regiones más afectadas. El río Piura se desbordó (...) e inundó varias calles de la capital del departamento. Las aguas llegaron hasta la Plaza de Armas de la ciudad e hicieron colapsar el sistema de drenaje. Los vecinos les pidieron a las autoridades el envío de motobombas e hicieron un llamado a los congresistas de Piura para que solucionen la emergencia. Las autoridades de la región desplegaron motobombas para extraer el agua en las zonas inundadas, pero hasta el momento es insuficiente. El gerente municipal de Piura, Luis Frías, reconoció que las máquinas no son suficientes para solucionar el problema y dijo que en los próximos días tendrán ocho más para la evacuación de agua (RPPNoticias, 2017).

Tras este fenómeno natural de grave impacto en el norte del país, Kuczynski como presidente y Vizcarra como ministro de Transportes y Comunicaciones (MTC), tuvieron que hacer frente al Caso Chinchero, que desencadenó efectos adversos para los políticos y funcionarios involucrados. El proyecto Chinchero trata de la construcción de un aeropuerto internacional para la ciudad del Cuzco, debido a que supuestamente la infraestructura del actual aeropuerto, Aeropuerto Internacional Alejandro Velasco Astete, no hace posible la implementación de las pistas necesarias para su operación internacional. Los últimos gobiernos han buscado acelerar su construcción pues señalan que repercutirá en mayores ingresos para dicha región y para el país. El polémico contrato se concertó en el gobierno de Ollanta Humala con el consorcio Kuntur Wasi, conformado por Andino Investment Holding (AIH) y Corporación América, que ganó la concesión del proyecto.

A finales del 2016, el gobierno de PPK anunció que iba a firmar una nueva adenda con Kuntur Wasi para modificar el contrato suscrito en la gestión de Humala. La concesionaria había ofrecido US\$ 265 millones para la construcción del aeropuerto. A cambio, el gobierno debía devolver ese monto más $22 \%$ de intereses. En total, una cifra de US\$ 587 millones. No era una ecuación justa. Pero, al menos, con ese contrato el Ejecutivo podía rechazar el acuerdo sin arbitraje de por medio. Para el 2 de diciembre de ese año, Kuntur Wasi ya había presentado una propuesta de adenda al MTC, entonces dirigido por Martín Vizcarra. El 20 de enero del 2017, el Consejo Directivo de Ositran se pronunció a favor de la adenda. La decisión fue apoyada por sus directores representantes Antonio Balbuena y Alfredo Dammert. El argumento radicó en que, a diferencia del primer contrato, este no iba a afectar al Estado peruano. Opinión distinta tuvo la directora de Ositran, Patricia Benavente, quien acotó entonces, que las primeras subetapas del proyecto se iban a realizar con US\$ 140 millones de fondos públicos. En medio de protestas desatadas en Cusco por el proyecto, el exministro de Transportes aprobó la firma de la adenda por Chinchero el 3 
de febrero del 2017. Vizcarra alegó que con ese acuerdo el ahorro sería de S/ 1.900 millones en intereses. El problema era que el Estado iba a asumir el $80 \%$ del financiamiento del proyecto. La consecuencia fue que el procurador anticorrupción Amado Enco denunció una presunta colusión de funcionarios del MTC y ejecutivos de Kuntur Wasi. Por eso, el 24 de febrero el Ministerio Público inició una investigación preliminar. Al mes siguiente, la Fiscalía Provincial Especializada en Delitos de Corrupción allanó las oficinas de Kuntur Wasi. (Sanchez, 2019, 9)

Tras la difusión de una imagen donde se apreciaba al presidente del directorio de Kuntur Wasi, Carlos Vargas Loret de Mola, y a otras autoridades del gobierno nacional, la Contraloría aplazó el informe sobre la adenda de Chinchero por un plazo de tres meses. Asimismo, el Congreso de la República, de mayoría fujimorista, aprovechó este contexto para presentar una interpelación en contra de Martín Vizcarra por el asunto de la adenda al contrato Chinchero. Las bancadas que concertaron la interpelación fueron Fuerza Popular, Frente Amplio, el APRA, Acción Popular. De este modo, en mayo de 2017, Martín Vizcarra fue interrogado por el parlamento que, al mismo tiempo, buscaba censurarlo por sus actos. Ante tales hechos, Vizcarra presentó su renuncia con anticipación para dimitir al cargo de ministro de Transportes y Comunicaciones. Por último, la Contraloría General de la República días después develaría la existencia de presuntos acuerdos irregulares que intervinieron en la adenda por el Contrato Chinchero; por consiguiente, se conseguiría denunciar a diez funcionarios involucrados en este megaproyecto.

El titular de Transportes y Comunicaciones, Martín Vizcarra, presentó su renuncia emitida desde el Palacio de Gobierno. La salida se da luego de los cuestionamientos y el retroceso en la construcción del aeropuerto de Chinchero, en el Cusco. Precisamente ese día de la renuncia presentada por el exministro Vizcarra, junto a Pedro Pablo Kuczynski, la Contraloría emitió el informe técnico que confirmó los vicios (RPPNoticias, 2017).

Después de todo lo sucedido por el Caso Chinchero, y después de la renuncia al cargo de ministro de Transportes y Comunicaciones, Vizcarra quedó absuelto de investigaciones preliminares que lo inculparan, ya que el Ministerio Público en febrero del 2018 no halló las pruebas suficientes para iniciar acciones legales en su contra. De igual forma, continuó su carrera política dentro del Estado. Esta vez solo como primer vicepresidente de la República, hasta que en diciembre de 2017 fue nombrado por Kuczynski como embajador del Perú en Canadá en reemplazo de Marcela López Bravo (RPPNoticias, 2017). De esta manera, se liberó de las acusaciones que recibía y su salida mermó las observaciones que el gobierno de PPK recibió. Para Gago (2019): “Martín Vizcarra pidió ser embajador en Canadá después de haber renunciado al Ministerio de Transporte y Comunicaciones (antes de ser censurado por el Congreso por la adenda 
suscrita del aeropuerto de Chinchero, en Cusco)". Vizcarra gozaba nuevamente de una oportunidad que lo alejó de críticas centrales y deterioraba sus acciones e imagen.

\section{Vizcarra presidente: las reformas políticas y la disolución del congreso}

Debido a la renuncia del expresidente Pedro Pablo Kuczynski, el ingeniero Martín Vizcarra Cornejo dio por concluido su cargo como embajador extraordinario y plenipotenciario en Canadá y asumió, en su calidad de primer vicepresidente, el cargo de presidente del Perú. De manera paradójica, era la agrupación fujimorista que lo había alejado del gobierno con acusaciones de corrupción (BBC, 2018a), la que alentó su reingreso al Ejecutivo (Mizrahi, 2019), tras promover la salida de Kuczynski. Este partido, sin embargo, pieza clave de una incesante crisis política, terminó siendo castigado en las urnas en las elecciones del 2019 (Menéndez, 2020). Algunas razones fueron por sus obstrucciones al Ejecutivo de Vizcarra, por su escaso protagonismo en el desarrollo del país y por la imagen negativa que se les atribuyó al percibirlos como un partido que propiciaba corrupción. La participación política censuró al fujimorismo (O’Donell, 2001), pero también a su aliado político, el aprismo (Di Tella, 2015). Al asumir el cargo más importante del país, Vizcarra enfatizó en su mensaje a la nación la lucha frontal contra la corrupción y, además, sostuvo que no permitiría la confrontación entre Ejecutivo y Legislativo, porque esta no aportaba ni influía positivamente en la solución de conflictos políticos (Riepl, 2019).

Vizcarra anunció que su gobierno convocaría a un referéndum para aprobar las reformas constitucionales, tanto del sistema judicial como del Congreso, con el fin de hacerle frente a la corrupción que parecía haberse apoderado de estos poderes del Estado (Jaramillo, 2019). Antes de poder ser sometidas a referéndum, el Congreso debía aprobar cuatro medidas: la reforma del Consejo Nacional de la Magistratura (CNM), la regulación del financiamiento privado a los partidos políticos, la no reelección inmediata de congresistas y el retorno a la bicameralidad. Fuerza Popular, aún el principal partido de oposición en el Congreso fue muy crítico de estas reformas, que las catalogó de populistas, en particular, la no reelección de congresistas (Ponce de León y García Ayala, 2019, p. 350).

Las reformas políticas fueron la estrategia para que Vizcarra sostuviera su discurso de lucha contra la corrupción y confrontara así al fujimorismo. La victoria que obtuvo el presidente luego de las votaciones para las reformas se reflejó en un alto nivel de aprobación por parte de la 
población, alcanzando un 66\% de respaldo. Asimismo, su aprobación se incrementaba cuando enfrentaba al Congreso con reformas o proyectos de ley que ameritaban relativa urgencia, como las reformas de Justicia.

Figura 1. Aprobación del presidente Martín Vizcarra tras el referéndum de las 4 reformas políticas

\section{¿APRUEBA O DESAPRUEBA LA GESTIÓN DE...? \\ El presidente Martín Vizcarra}

- APRUEBA DESAPRUEBA

Base: total de entrevistados

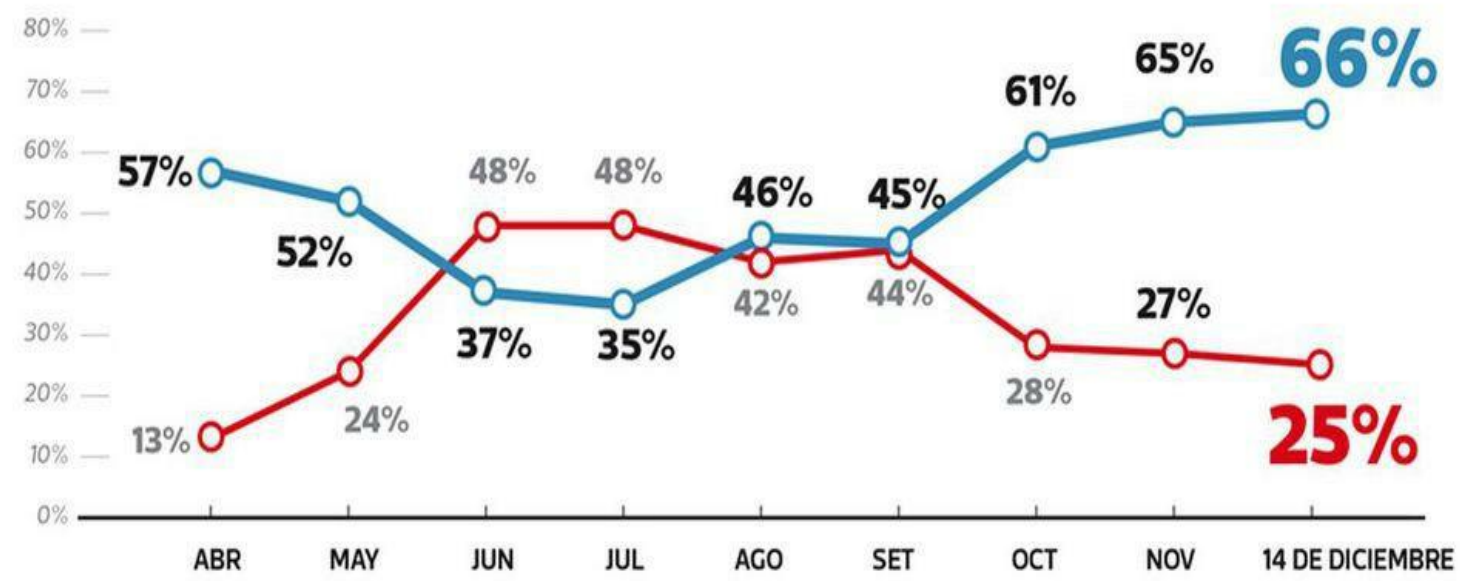

Fuente: Base de datos de El Comercio-IPSOS

Meses después, y aún con las denuncias en su contra que le tocó enfrentar tras su gestión como gobernador regional, y la polémica reapertura de una investigación llevada a cabo por la Contraloría en diciembre de 2019, Vizcarra continuó con las decisiones que comprometían al país. En septiembre de ese mismo año, la tensión entre el presidente y la mayoría parlamentaria se había intensificado, ahondada por las reformas que el fujimorismo desde el Congreso desnaturalizaba o modificaba para volverlos proyectos orientados a sus particulares intereses. En respuesta, el presidente planteó la primera cuestión de confianza, un procedimiento constitucional. Con ello, logró la aprobación de las cuatro reformas constitucionales. No obstante, solo unos meses después, se vio en la urgencia de presionar al Parlamento para aprobar las reformas políticas pendientes:

Esta vez, el mandatario fue más específico en lo que esperaba del Congreso si este decidía aprobarle la confianza. "La aprobación sin vulnerar la esencia de cinco proyectos de ley 
presentados", detalló. Luego puso ejemplos de qué era lo que buscaba. "Uno de estos proyectos busca que la inmunidad parlamentaria no se convierta en impunidad”, afirmó. El final de aquel discurso fue un nuevo llamado a la ciudadanía, figura que el presidente ha utilizado en casi todas sus intervenciones públicas desde aquel momento. El Congreso le dio la confianza al gabinete de Salvador Del Solar días después, pero luego aprobó modificaciones a la inmunidad parlamentaria que se alejaban de lo que el Ejecutivo había propuesto. (Benza, 2019, p. 13)

Frente a este escenario, la aprobación del presidente no logró superar más del cincuenta por ciento. Mediante una nueva medida de presión para confrontar a la oposición parlamentaria, Vizcarra decidió presentar una tercera cuestión de confianza debido a que el Congreso priorizó el proceso de selección de los miembros al Tribunal Constitucional (TC), lo que fue calificado por el Gobierno como un proceso sin transparencia y que no defendía la división de poderes. Por ello, al haberse nombrado al magistrado para el TC, el Ejecutivo consideró la denegación de esta tercera cuestión de confianza por parte de la mayoría fujimorista y sus aliados.

En un mensaje televisado, Vizcarra declaró que con la disolución del Congreso buscaba dar un fin a esta etapa de entrampamiento [conflicto de intereses que mellan la institucionalidad] político que ha impedido que Perú crezca al ritmo de sus posibilidades. Agregó que espera que esta medida excepcional permita que la ciudadanía finalmente se exprese y defina en las urnas y mediante su participación el futuro de nuestro país. Tras el anuncio, los responsables de las Fuerzas Armadas y la Policía Nacional se reunieron con Vizcarra para mostrar su pleno respaldo al orden constitucional y al presidente (BBC News Mundo, 2019).

De esta forma, Vizcarra, tras tomar la decisión constitucional de cerrar el Congreso con la denegación de la tercera cuestión de confianza y posibilitar, para el año siguiente, nuevas elecciones legislativas extraordinarias, manejó el escenario político a través de diferentes estrategias y reformas que le permitieron afrontar la constante amenaza institucional causada por la corrupción y una obstrucción parlamentaria. En esta pugna, consiguió mayor credibilidad y plausibilidad en los sectores populares que le mostraron respaldo al aprobar su mandato. En efecto, el discurso y desenvolvimiento erigido por Martín Vizcarra, y otras figuras políticas que lo acompañaron, puede interpretarse como una victoria política. 
Figura 2. Respaldo general tras la decisión tomada por el presidente de disolver el Congreso

\section{¿En general diría que aprueba o desaprueba la gestión de...?}

Base: total de entrevistados

\section{El presidente \\ MARTÍN VIZCARRA}

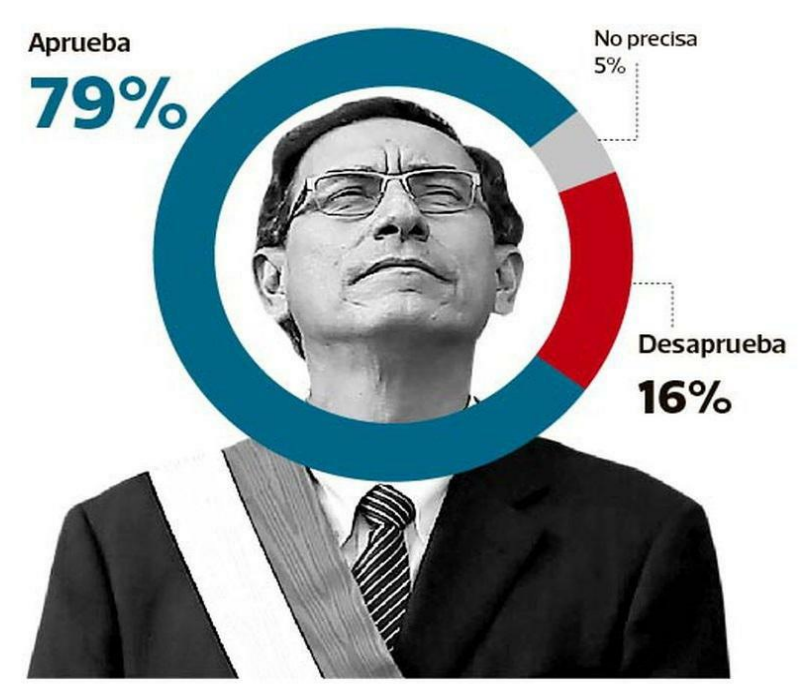

Fuente: Base de datos de El Comercio-IPSOS

\section{Vizcarra en la pandemia y presuntas irregularidades}

Luego de la disolución del Congreso de la República en el año 2019 y tras el adelanto a unas Elecciones Congresales Extraordinarias a finales de enero de 2020, otro suceso complicó el gobierno de Vizcarra: la pandemia del COVID-19. El 11 de marzo la Organización Mundial de la Salud (OMS) elevó la propagación del virus a pandemia, debido a su rápido nivel de expansión que tuvo en varios países del continente asiático y europeo.

La presencia del virus en el Perú fue oficializada el 6 de marzo de 2020, por lo que el gobierno peruano de Martín Vizcarra respondió rápidamente. El Poder Ejecutivo, junto a su gabinete ministerial y los diferentes niveles de gobierno a nivel nacional, iniciaron las primeras acciones de gobierno para contener el avance del coronavirus, principalmente a partir del establecimiento del confinamiento obligatorio nacional, desde el 16 de marzo. Para ello 
movilizaron a las fuerzas del orden, que fueron las encargadas de asegurar que la población acate la medida. Asimismo, el gobierno solicitó que todas las acciones realizadas en este marco sean revisadas paralelamente por la Contraloría.

No obstante, las precarias y deficientes condiciones con las que el país recibía la pandemia iban haciéndose más evidentes. La administración de Vizcarra enfrentó problemas de gestión por parte de las regiones y municipalidades, además de presuntos actos de corrupción que involucraronn a instituciones de la Policía:

El contralor Nelson Shack informó que su institución dará a conocer en las próximas semanas diversos informes sobre casos de presunta corrupción en las contrataciones realizadas por el Ministerio del Interior (Mininter) para la Policía Nacional (PNP). En RPP, indicó que en el marco del estado de emergencia nacional por el coronavirus (COVID-19), el Mininter recibió S/ 100 millones para la adquisición de equipos de bioseguridad y de protección destinados a los efectivos del orden. (Gestión, 2020)

A finales de marzo de 2020, la Contraloría General de la República, entidad fiscalizadora superior, dio a conocer sus nuevos plazos de procedimientos de control concurrente en el contexto del confinamiento obligatorio para poder supervisar y comunicar las acciones del gobierno con respecto al uso de los recursos y fondos públicos en beneficio de la población vulnerable. Estas facultades se aprobaron por el Congreso de la República en una sesión plenaria establecida por la emergencia del coronavirus. Por otra parte, el contralor general, Nelson Shack señaló que su entidad ha calculado realizar 1,980 intervenciones, de las cuales resultarán 4,500 como informes de control.

Durante la emergencia sanitaria se produjeron la destitución de dos ministros. El primero de ellos fue el caso de la exministra Elizabeth Hinostroza Pereyra que, a los pocos días de estar en el cargo como titular del ministerio de Salud, el presidente Martín Vizcarra oficializó su retiro y presentó a Víctor Zamora en su reemplazo, debido a que, según el jefe de Estado, se necesitaba en el puesto a un especialista en salud pública. En segundo lugar y tras las investigaciones a la Policía Nacional del Perú y la confirmación de decenas de policías contagiados, se dio a conocer la renuncia del ministro del Interior Carlos Morán Soto, que fue reemplado en el cargo por el general de la Policía Nacional, Gastón Rodríguez Limo. Al parecer este cambio se asociaba con presuntos actos de corrupción desde el gobierno:

En el contexto de la emergencia sanitaria por el nuevo coronavirus, Morán Soto fue cuestionado por los 1.300 policías contagiados con el infeccioso mal. Además, el Hospital 
de la Policía evidenció la falta de recursos para atender la demanda de agentes enfermos. Asimismo, se reportó posibles actos de corrupción en millonarias compras públicas de la PNP. En consecuencia, la Fiscalía Anticorrupción en regiones de Puno y Ayacucho investigan presuntas irregularidades de adquisiciones direccionadas y con sobrecosto (La República, 2020).

En medio de tales cuestionamientos, el nuevo ministro del Interior se le encomendó esclarecer los procesos de investigación que se le han abierto a diferentes agentes de la policía involucrados en los presuntos actos irregulares descubiertos por las autoridades competentes (Carreras, 2013). Caso que aún no se resuelve. Sobre Gastón Rodríguez Limo se advierte, asimismo, que recibió acusaciones en relación con un caso de corrupción sobre una red criminal que se dedicaba a cobrar de manera ilícita a comerciantes que ocupaban la vía pública en que el que se ha visto involucrado como testigo y que aparentemente ocultó (Servindi, 2020).

Si bien en los primeros días las medidas adoptadas por el gobierno de Vizcarra fueron aplaudidas por ser uno los países que más rápido actuó frente al virus, y esas acciones pesan aún a la fecha en su la aprobación a su gestión, que bordea el 50\% (El Espectador, 2020), Vizcarra muestra un gobierno débil, pues ejecuta una agenda coyuntural y no una agenda propia, que no escapa de acusaciones relacionadas con la corrupción.

\section{Reflexión sobre la gestión del presidente Vizcarra y su impacto en la política actual}

En el 2018 se publicó el Plan Bicentenario que contiene un plan estratégico de desarrollo nacional con miras al 2021. Su fin es convertir al Perú en un país democrático, desarrollado y cohesionado socialmente, a partir de la consecución de seis ejes: 1) los derechos fundamentales y dignidad de las personas, 2) las oportunidades y el acceso a los servicios, 3) el Estado y la gobernabilidad, 4) la Economía, la competitividad y el empleo, 5) el desarrollo regional y la infraestructura, 6) los recursos naturales y ambiente (CEPLAN, 2018). Al respecto, Vizcarra, en su rol como presidente se ha ido comprometiendo con dichas metas; sin embargo, no las logra y queda poco plazo para cumplirlas. En base a dicho Plan, Vizcarra busca que los peruanos se unan a la realización del proyecto. Para él, se trata de lograr alcanzar "las seis banderas del Bicentenario", las cuales ha ido invocando de la siguiente manera: 1) Por un país que lucha frontalmente contra la corrupción; 2) por un país que hace del diálogo su principal arma contra la violencia; 3) por un país integrado, moderno y competitivo; 4) por un país con igualdad de 
oportunidades para todos; 5) por un país sostenible y que es respetuoso de la naturaleza; y 6) por un país orgulloso de su identidad y diversidad (Gestión, 2018, párr. 2).

Juntos vamos a ganar esta batalla. La reforma que hemos planteado son parte de la agenda del bicentenario. No se trata de una agenda conmemorativa, sino de un conjunto de obras, acciones y actividades que desde distintos sectores estratégicos sientan las bases de ese Perú que todos queremos construir. Un Perú libre de corrupción, justo y con igualdad de oportunidades para todos (Gestión, 2018, párr. 3).

El Bicentenario se acerca y el gobierno de Vizcarra ha avanzado poco. En el 2019, CPI encuestó a la ciudadanía para saber cuál es el problema más grave que afronta el país y que debería ser resuelto de forma prioritaria por el gobierno del presidente Martín Vizcarra. La población consideró que los dos problemas son la "Delincuencia/falta de seguridad ciudadana" (40.7\%) y la “corrupción en general” (29.7\%) (CPI, 2019, p. 6). Con pandemia, y sin esta, siguen siendo las preocupaciones de la población, que no percibe que se estén resolviendo. Los apoyos que necesita Vizcarra para su agenda reformista son escasos. La fragmentación política y la falta de una bancada de gobierno no favorece plenamente su trabajo. Esto dificulta la gobernabilidad para alcanzar consensos y acuerdos entre los partidarios, necesarios para atender las demandas sociales.

Asimismo, los legisladores actuales se van oponiendo al gobierno, conforme se evidencia el descontento de la población ante una grave crisis económica provocada por la paralización de la mayor parte de actividades económico productivas por más de 60 días, con la que el Gobierno buscó evitar la propagación del virus. Esta medida provocó la pérdida de 2,6 millones de puestos de trabajo según cifras oficiales.

Por otro lado, el presidente ha estado cuestionado por la opinión pública debido a un presunto tráfico de influencias en el sector público al supuestamente haber intervenido a favor de la contratación de Richard Cisneros (cuyo nombre artístico es Richard Swing), cuyos supuestos vínculos datan cuando postulaba como primer vicepresidente en la campaña presidencial de 2016. Dentro del periodo del gobierno de Vizcarra, Cisneros realizó consultorías por más de 60.000 soles al Ministerio de Cultura del Perú. Además de esta acusación, también fueron hechas públicas por los medios de comunicación las contrataciones con el Estado de su cuñado y un familiar de la secretaria general del Despacho de la Presidencia.

Al tiempo que el presidente construye una imagen de estadista en pandemia, su entorno y sus relaciones la quiebran. Vizcarra no cuenta con un partido político, dado que el que lo llevó al 
gobierno se diluyó, y los partidos afines en los que podía respaldarse, como los centroderecha Acción Popular o Partido Morado, no alcanzan una mayoría en el Parlamento. Además, Acción Popular, que obtuvo más escaños, ha ido perdiendo popularidad por sus pugnas internas por el liderazgo del mismo. Quitral (2012) sostiene que, en el camino hacia los bicentenarios, América Latina está enfrentada por la agudización de sus problemáticas internas, cuotas de ingobernabilidad y la desestabilización institucional en los gobiernos de turno.

El Perú, a diferencia de otros países de la región, ha logrado avances en las investigaciones por los casos de corrupción de sus altos funcionarios. Ollanta Humala, por ejemplo, se enfrenta a un pedido de la Fiscalía de 20 años de prisión; Alejandro Toledo está detenido en EE. UU. mientras se resuelve un pedido de extradición de la Justicia peruana; y Pedro Pablo Kuczynski, su antecesor, permanece con arresto domiciliario. Con esos antecedentes, no sería una sorpresa que Martín Vizcarra, una vez que termine su mandato, pase a ser investigado por los casos que parece dejar pendiente.

En este contexto, la pugna por la lucha anticorrupción es paradójica. El Legislativo acusa al Ejecutivo del blindaje a magistrados con acusaciones graves y de encubrir actos de corrupción y el Ejecutivo acusa de lo mismo a cada Legislativo, sobre todo a los partidos políticos tradicionales, que aún tienen influencia en el Parlamento (Perú21, 2019b). En este desencuentro, Vizcarra aún tiene el respaldo de la ciudadanía, por el marcado desprestigio del Legislativo.

Vizcarra, asimismo, parece buscar acelerar la culminación de su gobierno. Ya ha establecido la fecha para las elecciones generales en el 2021. Saluda y apresura la celebración de obras públicas, sobre todo las que colaboran a combatir la propagación del virus, en medio de reclamos por la ausencia de bonos a diferentes sectores sociales, a los cuales va atendiendo para satisfacer los reclamos (él ha entregado el bono 380 soles, el bono independiente, el bono rural, el bono familia universal, el bono PNP, el bono transportista, el bono 760 soles, y la pensión de orfandad a víctimas del COVID-19). Aún así, muchas de las obras públicas han sufrido retrasos en su implementación por desencuentros entre el gobierno central con los gobiernos regionales. Las regiones acusan al gobierno de Vizcarra de no entregar las obras con los recursos necesarios; por ejemplo, señalan que las obras no cuentan con balones de oxígeno para cada cama de Unidad de Cuidados Intensivos (UCI). No obstante, el desencuentro entre el gobierno central y las regiones no es algo nuevo. Este se vio amplificado en el sur del país en 2019, cuando se intensificaron los 
conflictos sociales por la presencia de empresas extractivas de minerales. Vizcarra ha tratado de evitar mayores confrontaciones y trata de atender las demandas sociales, con toda la presión que recibe incluso de los empresarios. Combate el decrecimiento económico afectado por la crisis política y la crisis internacional, mientras proyecta dejar una buena imagen política. En sus discursos oficiales ha insistido, al igual que sus predecesores, en continuar con los modelos económicos neoliberales, extractivistas y de inversión privada (Lovón, 2020), como alternativas para la reactivación de la economía. Como una medida popular trabaja en lo que el gobierno llama impuesto solidario a los ricos.

De no ser vinculado con actos de corrupción grave, en un tiempo podría presentarse como candidato a la presidencia de la República, aunque ha negado su postulación y ha rechazado continuar un gobierno inmediato, más aun si la Constitución lo prohíbe. Vizcarra al parecer confía primero en la presentación de algún actor político más cercano a su gobierno, como su exministro Salvador del Solar, quien está entre los preferidos en la intención de voto para las siguientes elecciones, o el alcalde de La Victoria, George Forsyth, con quien ha tenido encuentros amistosos para tratar asuntos a favor del ciudadano. Forsyth es otro de los preferidos sobre todo en la capital de Lima, donde se encuentra la mayor cantidad de electores.

A nivel regional e internacional, mantiene un diálogo con presidentes del Grupo de Lima, China y EE. UU., pero mantiene sus discrepancias con el gobierno venezolano y sus simpatizantes. Desde que inició la pandemia, Vizcarra no se ha pronunciado por el sistema democrático observado en Venezuela y tampoco en Perú ha tratado el tema de la migración venezolana, ciudadanos que han ido dejando el país a pie incluso y de retorno al suyo, sin recibir algún bono especial, bajo el aumento de desempleo que afecta tanto a los peruanos como a ellos. El gobierno ha preferido mantener un silencio en lo absoluto para evitar abrir fricciones con los connacionales y entramparse en temas que podrían desatender su labor contra la difusión del virus en un país donde se incrementa y que el mundo observa como peligroso. Italia, por ejemplo, cerró fronteras con Perú. De los países latinoamericanos, México, Brasil y Perú presentan altas tasas de infecciones. Y en el Perú la población no solo le reclama por una salud sanitaria digna y justa, sino también por trabajo digno y justo, sobre todo porque el Perú es un país con sectores laborales informales altos y en el que muchas familias no gozan de bienestar económico social. El Perú es uno de los países con altas tasas de informalidad, aglomeraciones en la calle y hacinamientos en 
casa. Vizcarra será recordado como el presidente del gobierno que contuvo la COVID-19 con limitaciones heredadas, pero también generadas. A pesar de los diversos confinamientos, su gestión no rastreó los contactos de contagios por coronavirus. En su último mensaje presidencial no ha sostenido un discurso de reconstrucción post COVID-19.

\section{Observaciones finales}

El Perú, como se ha visto, ha sufrido cambios políticos muy complejos desde décadas anteriores (Muñoz, \& Guibert, 2020, Lovón, 2018) al gobierno de Vizcarra. Su gestión, que se apoya en un simbolismo de transición, no ha podido despercurdirse del grave deterioro de la clase política del país, que se hizo más evidente a la opinión pública a partir de las revelaciones del escándalo de corrupción Lava Jato (McNulty, 2019). Martín Vizcarra, a diferencia de la administración de Pedro Pablo Kuczynski, supo inicialmente orientar la polarización y confrontación del Ejecutivo y el Legislativo, a la consecución de un mayor apoyo popular, mediante la defensa de medidas anticorrupción. Ello le permitió, a partir de mecanismos constitucionales, continuar su gobierno con buenos índices de popularidad, mejor sostenidos en el tiempo que sus dos antecesores gobernantes.

Las más de 30 denuncias que se le vinculan a Vizcarra, según la Procuraduría de Moquegua, por presuntos casos de corrupción o pagos irregulares al finalizar sus funciones como gobernador regional de Moquegua, no representaron quiebre alguno para su carrera política. Vizcarra, como hemos visto, ha manifestado que sus denuncias no lograron fundamentarse a causa de falta de pruebas, y la gravedad de la pandemia ha contribuido en que el foco mediático no se centre en estas.

Interesa señalar que, como actor político, el actual jefe de Estado no ha actuado de manera indiferente frente a las acusaciones de corrupción, y más bien estratégicamente se ha manifestado de manera activa al promover la lucha anticorrupción. Él ha atravesado diversos escenarios adversos: el primero de ellos se remonta al año 2011, cuando era gobernador regional de Moquegua y donde tuvo un papel sustantivo en el desarrollo de esta región, pero además fue acusado de una presunta irregularidad en la adjudicación de un proyecto; el segundo escenario abarca su etapa como ministro de Transportes y Comunicaciones, donde se le cuestionó sobre todo por la adenda de la obra del aeropuerto de Chinchero; en tercer lugar, se encuentra el trayecto de Vizcarra como jefe de Estado, y el enrevesado papel que atravesó para sacar adelante reformas políticas que, para 
su aprobación, devinieron en una disolución constitucional del Congreso (Carranza, 2019). Como presidente, en plena pandemia, carece del apoyo sustancial de diversos sectores económicos, políticos, sociales, a la vez que la media va difundiendo acusaciones sobre corrupción. Al parecer, su falta de aliados, lo hacen querer culminar su presidencia sin más contratiempos. Una lectura de su comportamiento, es que prefiere manejar una imagen de demócrata pegado a la Constitución, que le permita mantener su popularidad aún en un escenario económico adverso.

Una explicación para entender por qué no se establece una relación profunda entre Vizcarra y la corrupción se debe a sus actuaciones. Las iniciativas de Vizcarra, a los ojos del sector que lo apoya y que legitima su gestión, reflejaron una recuperación de la democracia y de la estabilidad institucional (Altman, y Pérez-Liñán, 2002) con él en el gobierno. En los últimos años, los quiebres políticos e institucionales que atiborraron su carrera como funcionario y como presidente de la República encuentran credibilidad en la participación ciudadana y en las supuestas célebres reformas estructurales que impulsó para combatir y frenar el poder que representaron algunas fuerzas políticas dentro del Estado peruano (Mann, 2004). Cabe señalar que una de sus estrategias discursivas populares es la apelación a la cuota de género. Vizcarra impulsa la paridad y la alternancia de género en las listas de candidatos al Congreso peruano. Y en pandemia, por ejemplo, ha dado declaraciones en varias conferencias presidenciales para informar a la población sobre la situación del país, a diferencia de otros presidentes en Latinoamérica, hasta incluso anunciar errores políticos, como una manera de continuar su conexión con la población.

Otra estrategia que lo favorece es la lucha contra el supuesto tráfico de influencias y lobbys de las empresas de educación superior creadas a partir de la ley universitaria de 1996, durante el mandato de Alberto Fujimori (1990-2000), que promovía la inversión en la educación superior privada, permitiendo la creación de universidades privadas con fines de lucro. Con esta ley, que se encuentra por ahora en moratoria, Perú llegó a tener un total de 145 de estas instituciones, entre públicas y privadas, sin que ello garantice una enseñanza de calidad ni mayor investigación. El gobierno de Vizcarra ha señalado que los congresistas han apoyado la creación de universidades empresa que no acreditan calidad educativa, pero enriquece a sus administradores y aliados, entre ellos congresistas que han estudiado en esas universidades o poseen acciones en ellas. Vizcarra defiende el papel que ha tenido la Superintendencia Nacional de Educación Superior (SUNEDU), organismo adscrito al Ministerio de Educación y creado durante el gobierno de Ollanta Humala. 
La distancia que marca Vizcarra frente a ese poder económico de las universidades empresa, le ha permitido también reforzar una imagen de anticorrupción.

En su último año de mandato, Vizcarra no parece aún haberse resignado en el cargo como jefe de Estado pese a las críticas que recibe por su gestión y el pasado que le ronda. Sus gabinetes ministeriales han sido el principal blanco de embates por el papel de su actuación que llevan a cabo en el marco de la emergencia sanitaria por la COVID-19. En menos de dos años ha tenido hasta más de cinco cambios de gabinetes. El Legislativo censuró por ejemplo al gabinete liderado por Pedro Cateriano por no haber contado con un plan específico para enfrentar el coronavirus y haberse presentando con algunos ministros con escasa experiencia. Ello condujo a Vizcarra a proponer un nuevo equipo ministerial que el Legislativo actual aceptó en este marco. Las actuaciones de Vizcarra como presidente son muestras de la escasa interacción entre el Poder Ejecutivo y el Poder Legislativo de un país con democracia representativa frágil cuyas reformas se detienen y en donde cada actor político es observado por gestiones anteriores.

\section{Referencias}

Ackerman, B. (2007). La nueva división de poderes. Ciudad de México: Fondo de Cultura Económica.

Acevedo, J. (2017). ¿A la deriva? Los problemas político-comunicativos de PPK. Más Poder Local, 33, 34-40.

Alcántara, M. \& Sánchez López, F. (2001). Las relaciones ejecutivo-legislativo en América Latina: un análisis de la estructura de veto-insistencia y control político. Revista de Estudios Políticos (Nueva Época), 112.

Altman, David \& Aníbal Pérez-Liñán (2002). Assessing the Quality of Democracy: Freedom, Competitiveness and Participation in Eighteen Latin American Countries. Democratization, 9(2), 85-100.

Andina. (05 de febrero de 2019). Maduro ya no es legítimo presidente de Venezuela, afirma Vizcarra. Recuperado de https://andina.pe/agencia/noticia-maduro-ya-no-es-legitimopresidente-venezuela-afirma-vizcarra-741535.aspx

Arce, M., \& Incio, J. (2018). Perú 2017: un caso extremo de gobierno dividido. Revista de ciencia política 38(2), 361-377. https://dx.doi.org/10.4067/s0718-090x2018000200361

BCC News Mundo. (23 de marzo de 2018a). Renuncia de PPK: quién es Martín Vizcarra, el exministro al que el fujimorismo acusó de corrupción y al que convirtió en presidente de Perú. Recuperado de https://www.bbc.com/mundo/noticias-america-latina-43494367 
BCC News Mundo. (19 de julio de 2018b). Perú: las conversaciones privadas de unos jueces que causaron la caída del presidente del Poder Judicial, Duberlí Rodríguez. Recuperado de https://www.bbc.com/mundo/noticias-america-latina-44830508

BCC News Mundo. (7 de diciembre de 2018c). Referéndum en Perú: por qué el presidente Martín Vizcarra rechaza una reforma que él mismo propuso. Recuperado de https://www.bbc.com/mundo/noticias-america-latina-46460016

BBC News Mundo. (2 de octubre de 2019). Disolución del Congreso en Perú: 4 claves para entender el enfrentamiento entre Vizcarra y el Parlamento (y lo que puede pasar ahora). Recuperado de https://www.bbc.com/mundo/noticias-america-latina-49887706

Benza, P. (27 de septiembre de 2019). Así fueron las dos primeras cuestiones de confianza del presidente Martín Vizcarra. Recuperado de https://elcomercio.pe/politica/asi-fueron-lasdos-primeras-cuestiones-de-confianza-del-presidente-martin-vizcarra-noticia/?ref=ecr

Campos, M. (2014). Relaciones ejecutivo-parlamento: grupos parlamentarios y mecanismos de control político en el Poder Ejecutivo. Lima: Pontificia Universidad Católica del Perú.

Carbonell, J.C. (2006). Perú: la necesidad de una reforma constitucional. Un punto de partida. Araucaria: Revista Iberoamericana de Filosofía, Política y Humanidades, 15, 157-175.

Carranza, D. (01 de octubre de 2019). Presidente Martín Vizcarra disolvió el Congreso de Perú. $A A$. Recuperado de https://www.aa.com.tr/es/mundo/presidente-mart\%C3\%ADnvizcarra-disolvi\%C3\%B3-el-congreso-de-per\%C3\%BA/1598430

Carreras, M. (2013). Presidentes outsiders y ministros neófitos: un análisis a través del ejemplo de Fujimori. América Latina Hoy, 64, 95-118.

Centro Nacional de Planeamiento Estratégico (CEPLAN). (2018). Plan Bicentenario. El Perú hacia el 2021. Lima: Ministerio de Economía y Finanzas (MEF). Recuperado de https://www.mef.gob.pe/contenidos/acerc_mins/doc_gestion/PlanBicentenarioversionfina l.pdf

Compañía Peruana de Estudios de Mercados y Opinión Pública (CPI). (2018). Los siete primeros meses del Gobierno del presidente Martín Vizcarra. Lima. Recuperado de https://www.cpi.pe/images/upload/paginaweb/archivo/23/opnac_evaluacion_7_meses_vi zcarra_presidente_peru_201810.pdf

Compañía Peruana de Estudios de Mercados y Opinión Pública (CPI). (2019). Evaluación ciudadana de la gestión del presidente Martín Vizcarra. Lima. Recuperado de http://cpi.pe/images/upload/paginaweb/archivo/23/opnac_evaluacion_vizcarra_presidente _peru_201906.pdf

Coelho, A. (2012). Inestabilidad política y caídas presidenciales en Sudamérica: causas y consecuencias. Política, 50(1), pp. 167-194. Recuperado de https://www.redalyc.org/pdf/645/64523929007.pdf

Cuba, E. (2018). El plan de gobierno de PPK, la política económica de Vizcarra y algo más. Ideele. Revista del Instituto de Defensa Legal, 281. Recuperado de https://revistaideele.com/ideele/content/el-plan-de-gobierno-de-ppk-la-pol\%C3\%ADticaecon\%C3\%B3mica-de-vizcarra-y-algo-m\%C3\%A1s 
Di Tella, T. (2015). Coaliciones Políticas. La Argentina en perspectiva. Buenos Aires: El Ateneo.

DW (10 de febrero de 2017). "Caso Odebrecht”: imputaciones en medio continente. Recuperado de https://www.dw.com/es/caso-odebrecht-imputaciones-en-medio-continente/a37489511

El Comercio (29 de enero de 2018). Los presuntos vínculos de PPK y Odebrecht en cinco puntos. Recuperado de https://elcomercio.pe/politica/presuntos-vinculos-ppk-odebrecht-cincopuntos-noticia-492989-noticia/

El Espectador (03 de abril de 2020). Perú, el buen ejemplo de América Latina en el manejo del coronavirus. Recuperado de https://www.elespectador.com/coronavirus/peru-el-buenejemplo-de-america-latina-en-el-manejo-del-coronavirus-articulo-912864

Fowks, J. (26 de marzo de 2018). Martín Vizcarra asume como presidente de Perú: 'Pongamos punto final a la confrontación'. https://elpais.com/internacional/2018/03/23/america/1521829723_964634.html

Gago, M. (2019). Vizcarra huye otra vez. En Canadá triunfó su desapego y frivolidad. Recuperado de https://elmontonero.pe/columnas/vizcarra-huye-otra-vez

García, E. (2007). El concepto de actor: Reflexiones y propuestas para la ciencia política. Andamios, $\quad 3(6), \quad 199-216 . \quad$ Recuperado de https://andamios.uacm.edu.mx/index.php/andamios/article/view/333

Gestión. (27 de mayo de 2016a). Fuerza Popular: "Vizcarra tiene 34 denuncias hechas por procurador de gobierno de Moquegua”. https://gestion.pe/peru/politica/fuerza-popularvizcarra-34-denuncias-hechas-procurador-gobierno-moquegua-146180-noticia/

Gestión. (10 de noviembre de 2018). Vizcarra al lanzar agenda Bicentenario: 'Nuestra batalla ahora es contra la corrupción'. Recuperado de https://gestion.pe/peru/politica/vizcarranuestra-batalla-urnas-acabar-corrupcion-nndc-249580-noticia/?ref=gesr

Gestión. (25 de abril de 2020). Contraloría dará a conocer informes de casos de presunta corrupción en la Policía. Gestión. Recuperado de https://gestion.pe/peru/politica/coronavirus-peru-contraloria-dara-a-conocer-informes-decasos-de-presunta-corrupcion-en-contrataciones-para-la-policia-nacional-covid-19-nndcnoticia/?ref=gesr

Jaramillo, C. (2019). Cuando caen los chicos y no los grandes: la corrupción a nivel subnacional en los casos de Callao y Tumbes. Politai, 10(18), 9-39. Recuperado a partir de http://revistas.pucp.edu.pe/index.php/politai/article/view/21171

LaMula.pe. (04 de septiembre de 2018). Pedro Chávarry abre una investigación preliminar por el caso Chinchero El fiscal de la Nación abrió una indagación inicial por 60 días en contra del exministro de Economía, Alfredo Thorne, que incluye a PPK y el ex contralor Edgar Alarcón, pero podría alcanzar al presidente Vizcarra. https://redaccion.lamula.pe/2018/09/04/pedro-chavarry-abre-investigacion-por-el-casochinchero/redaccionmulera/

Mizrahi, D. (05 de octubre de 2019). Martín Vizcarra, el líder menos pensado: del "exilio" en Canadá a la lucha contra la "casta política" en Perú. Infobae. Recuperado de 
https://www.infobae.com/america/america-latina/2019/10/06/martin-vizcarra-el-lidermenos-pensado-del-exilio-en-canada-a-la-lucha-contra-la-casta-politica-en-peru/

La República. (27 de abril de 2020). Ministro Rodríguez deberá indagar sobre presuntas compras irregulares de la PNP. Recuperado de https://larepublica.pe/politica/2020/04/26/coronavirus-gaston-rodriguez-debera-detectarpresuntos-actos-de-corrupcion-en-compras-de-la-pnp/

La Tercera. (09 de enero de 2019). El ataque de Maduro contra Vizcarra tras prohibición de entrar a Perú: "No me sé el nombre ni cómo llegó a ser presidente". Recuperado de https://www.latercera.com/mundo/noticia/ataque-maduro-vizcarra-tras-prohibicionentrar-peru-no-me-se-nombre-llego-presidente/477896/

Laufer, R. (2019). ¿Cómo afecta a Latinoamérica la guerra comercial China-EE.UU.? Asialink. Recuperado de https://asialink.americaeconomia.com/columna/como-afectalatinoamerica-la-guerra-comercial-china-eeuu

Lezama, C. (24 de marzo de 2018). Plan de desarrollo de Moquegua denota liderazgo. El Peruano. Recuperado de http://www.ipe.org.pe/portal/wp-content/uploads/2018/03/2018-03-24Plan-de-desarrollo-de-Moquegua-denota-liderazgo-El-Peruano.pdf

León, R. (2019). Vizcarra: retrato de un poder en construcción. Lima: Editorial Debate.

Lovón, M. (2020). The Discourse of Economic Growth in Peru: Analysis of the Presidential Messages in the Governments of Pedro Pablo Kuczynski and Martín Vizcarra. LL Journal, 15(1), 1-48. Recuperado de https://lljournal.commons.gc.cuny.edu/lovon/

Lovón, M. (2018). El legado lingüístico del fujimorismo. Boletín de la Academia Peruana de la Lengua, 63(63), 77-96. https://doi.org/10.46744/bapl.201801.003

Lovón, M. \& Pita, Sh. (2016). Los términos de la crisis venezolana. Boletín de Lingüística, (28), 45-46. Recuperado de http://saber.ucv.ve/ojs/index.php/rev_bl/article/view/14788

Mäckelmann, M. (2017). Los cuentos de los presidentes. Storytelling e historias biográficas en el mensaje de Pedro Pablo Kuczynski. Contratexto, 28, 173-195. Recuperado de https://revistas.ulima.edu.pe/index.php/contratexto/article/viewFile/1540/1805

Mann, M. (2004). La crisis del Estado-nación en América Latina. Desarrollo Económico. Revista de Ciencias Sociales, 44(174), 179-198.

McNulty, S. (2019). Perú 2016: continuidad y cambio en un año electoral. Revista de Ciencia Política, 37(2), pp. 563-587. https://doi.org/10.4067/s0718-090x2017000200563.

Menendez, C. (27 de enero de 2020). Perú castiga a los fujimoristas, que se hunden en las urnas. EuroNews. Recuperado de https://es.euronews.com/2020/01/27/peru-castiga-a-losfujimoristas-que-se-hunden-en-las-urnas

Muñoz, P., \& Guibert, Y. (2020). Perú: El fin del optimismo. Revista de Ciencia Política, 36(1), 313-338. https://doi.org/10.4067/S0718-090X2016000100014.

O’Donell, G. (2001). Accountability horizontal: la institucionalización legal de la desconfianza política. Revista Española de Ciencia Política, 11, 11-31. 
Pereda, D. (6 de diciembre de 2019). Edmer Trujillo: "Si no hacíamos adelanto del pago, se iba a paralizar la obra del Hospital de Moquegua”. La República. Recuperado de https://larepublica.pe/politica/2019/12/06/edmer-trujillo-si-no-haciamos-adelanto-delpago-se-iba-a-paralizar-la-obra-del-hospital-de-moquegua-mtc-contraloria-martinvizcarra-mdga/

Perú21. (14 de enero de 2019a). Carlos Tubino sostiene que el presidente Martín Vizcarra "no ha sido transparente". Recuperado de https://peru21.pe/politica/carlos-tubino-presidentemartin-vizcarra-sido-transparente-nndc-453144-noticia/?ref=p21r

Perú21. (29 de mayo de 2019b). Martín Vizcarra sobre el Congreso: "Hemos observado un descarado blindaje”. Recuperado de https://peru21.pe/politica/martin-vizcarra-congresohemos-observado-descarado-blindaje-481317-noticia/

Ponce de León, Z., \& García Ayala, L. (2019). Perú 2018: la precariedad política en tiempos de Lava Jato. Revista de Ciencia Política, 39(2), 341-365. https://doi.org/10.4067/S0718090X2019000200341.

Quitral, M. (2012). Crisis y Bicentenario: Algunas consideraciones económico-sociales. Revista Latinoamericana de Desarrollo Económico, (18), 177-199. Recuperado de https://www.lajed.ucb.edu.bo/index.php/a/article/view/a118

Riepl, M. (2019). Vizcarra. Una historia de traición y lealtad. Editorial Planeta.

Rocha, L. (2019). Brasil, Perú, Ecuador y Colombia firmarán un pacto por el Amazonas. Infoabe. Recuperado de https://www.infobae.com/america/america-latina/2019/09/05/brasil-peruecuador-y-colombia-firmaran-un-pacto-por-el-amazonas/

Rojas, G. V. (6 de diciembre de 2019). El Comercio. Recuperado de https://elcomercio.pe/politica/martin-vizcarra-develan-irregular-pago-de-mas-de-s41millones-en-su-gestion-como-gobernador-regional-de-moquegua-noticia/?ref=ecr

Rojas, G. V. (6 de diciembre de 2019). Martín Vizcarra: Develan irregular pago de más de S/41 millones en su gestión como gobernador de Moquegua. Recuperado de https://elcomercio.pe/politica/martin-vizcarra-develan-irregular-pago-de-mas-de-s41millones-en-su-gestion-como-gobernador-regional-de-moquegua-noticia/?ref=ecr

RPPNOTICIAS. (20 de octubre de 2010). En primera vuelta: Moquegua tiene nuevo presidente regional. Recuperado de https://rpp.pe/peru/actualidad/en-primera-vuelta-moqueguatiene-nuevo-presidente-regional-noticia-304284?ref=rpp

RPPNOTICIAS. (12 de marzo de 2017a). Fenónemo El Niño azota al Perú con lluvias, huaicos e inundaciones. Recuperado de https://rpp.pe/peru/actualidad/infografia-mapa-de-lasconsecuencias-del-fenomeno-el-nino-en-peru-noticia-1036328?ref=rpp

RPPNOTICIAS. (22 de mayo de 2017b). ¿Por qué renunció Martín Vizcarra al Ministerio de Transportes? Recuperado de https://rpp.pe/politica/gobierno/por-que-renuncio-martinvizcarra-al-ministerio-de-transportes-noticia-1052272?ref=rpp

RPPNOTICIAS. (28 de septiembre de 2017c). Martín Vizcarra fue nombrado embajador del Perú en Canadá https://rpp.pe/politica/gobierno/martin-vizcarra-fue-nombrado-embajador-delperu-en-canada-noticia-1079423 
RPPNOTICIAS. (23 de marzo de 2018). Las cifras de la gestión de Martín Vizcarra como gobernador regional de Moquegua. Recuperado de https://rpp.pe/politica/estado/martinvizcarra-y-las-metas-que-consiguio-cuando-fue-gobernador-regional-de-moqueguanoticia-1112323?ref=rpp

RPPNOTICIAS. (6 de diciembre de 2019). Enco: "Informe de Contraloría sobre pago irregular para hospital justifica la reapertura del caso". Recuperado de https://rpp.pe/politica/judiciales/martin-vizcarra-amado-enco-informe-de-la-contraloriasobre-pago-irregular-para-hospital-de-moquegua-justifica-la-reapertura-del-caso-noticia1233449.

RPPNOTICIAS. (6 de diciembre de 2019). Bruce: Vizcarra entró en plancha porque había 'demasiados blancos' y 'necesitábamos un provinciano'. Reecuperado de https://rpp.pe/politica/gobierno/carlos-bruce-martin-vizcarra-entro-en-plancha-porquehabia-demasiados-blancos-y-necesitabamos-un-provinciano-noticia-1201132

RTV. (30 de julio de 2019). RTV Economía: Vizcarra: 'Perú sufre los impactos de la desaceleración económica mundial'. Recuperado de https://rtv.pe/programas/rtveconomia/vizcarra-peru-sufre-los-impactos-de-la-desaceleracion-economica-mundial-rtveconomia-4135

Sanchez, D. Q. (29 de agosto de 2019). El Caso Chinchero: La historia de la adenda del aeropuerto. La República. Recuperado de https://larepublica.pe/politica/2019/08/29/elcaso-chinchero-la-historia-de-la-adenda-del-aeropuerto-cusco-kuntur-wasi-ministerio-detransportes/

Servindi. (06 de mayo de 2020). Crisis: corrupción y nombramientos cuestionados golpean al Mininter. Recuperado de https://www.servindi.org/actualidad-noticias/05/05/2020/crisisinterior-corrupcion-y-cuestionados-nombramientos-golpean-al

Soto Velasco, Sebastián. (2018). La vieja y la nueva separación de poderes en la relación entre el Poder Ejecutivo y el Poder Legislativo. Estudios constitucionales, 16(2), 449-480. https://dx.doi.org/10.4067/S0718-52002018000200449

Tanaka, M. (2019). Los estudios políticos en Perú: ausencias, desconexión de la realidad y la necesidad de la ciencia política como disciplina. Revista de Ciencia Política, 25(1), 222231. https://doi.org/10.4067/S0718-090X2005000100017.

Urdinez, Francisco. (2017). Las Relaciones triangulares: Sobre cómo la hegemonía de Estados Unidos ha condicionado la asertividad china en América Latina. Berlín: Red China y América Latina: Enfoques Multidisciplinarios (REDCAEM).

Wayka. (2019). Amazonía brasileña se incendia y Bolsonaro minimiza desastre. Recuperado de https://wayka.pe/amazonia-brasilena-se-incendia-y-bolsonaro-minimiza-desastre/ 